\title{
Estrogen-related receptors alpha, beta and gamma expression and function is associated with transcriptional repressor $\mathrm{EZH} 2$ in breast carcinoma
}

\author{
Kanchan Kumari ${ }^{1}$, Amit K. Adhya ${ }^{2}$, Arabinda Kumar Rath ${ }^{3}$, P. B. Reddy ${ }^{4}$ and Sandip K. Mishra ${ }^{1 *}$
}

\begin{abstract}
Background: Orphan nuclear receptors ERRa, ERR $\beta$ and ERRY that belong to NR3B or type IV nuclear receptor family are well studied for their role in breast cancer pathophysiology. Their homology with the canonical estrogen receptor dictates their possible contributing role in mammary gland development and disease. Although function and regulation of ERRa, ERRY and less about ERRß is reported, role of histone methylation in their altered expression in cancer cells is not studied. Transcriptional activity of nuclear receptors depends on co-regulatory proteins. The present study for the first time gives an insight into regulation of estrogen-related receptors by histone methylation specifically through methyltransferase EZH2 in breast cancer.

Methods: Expression of ERRa, ERRß, ERRY and EZH2 was assessed by immunohistochemistry in four identical tissue array slides that were prepared as per the protocol. The array slides were stained with ERRa, ERR $\beta$, ERRY and EZH2 simultaneously. Array data was correlated with expression in MERAV expression dataset. Pearson correlation coeficient $r$ was calculated from the partial matrix expression values available at MERAV database to study the strength of association between $\mathrm{EZH} 2$ and three orphan nuclear receptors under study. By western blot and real time PCR, their correlated expression was studied in breast cancer cell lines MCF-7, MDA-MB-231, T47D and MDAMB-453 including normal breast epithelial MCF-10A cells at both protein and RNA level. Regulation of ERRa, ERR $\beta$, ERRY by EZH2 was further investigated upon overexpression and silencing of EZH2. The interaction between ERRs and EZH2 was validated in vivo by CHIP-qPCR.
\end{abstract}

Results: We found a negative correlation between estrogen-related receptors and Enhancer of Zeste Homolog 2, a global repressor gene. Immunohistochemistry in primary breast tumors of different grades showed a correlated expression of estrogen-related receptors and EZH2. Their correlated expression was further validated using online MERAV expression dataset where a negative correlation of variable strengths was observed in breast cancer. Ectopic expression of EZH2 in low EZH2-expressing normal breast epithelial cells abrogated their expression and at the same time, its silencing enhanced the expression of estrogen-related receptors in cancerous cells. Global occupancy of EZH2 on ERRa and ERR $\beta$ was observed in-vivo.

Conclusion: Our findings identify EZH2 as a relevant coregulator for estrogen-related receptors in breast carcinoma. Keywords: EZH2, Orphan nuclear receptors, Breast cancer

\footnotetext{
* Correspondence: sandipkmishra@hotmail.com

${ }^{1}$ Cancer Biology Laboratory, Department of Gene Function and Regulation,

Institute of Life Sciences, Bhubaneswar. Utkal University, Bhubaneswar,

Odisha, India

Full list of author information is available at the end of the article
}

(c) The Author(s). 2018 Open Access This article is distributed under the terms of the Creative Commons Attribution 4.0 International License (http://creativecommons.org/licenses/by/4.0/), which permits unrestricted use, distribution, and reproduction in any medium, provided you give appropriate credit to the original author(s) and the source, provide a link to the Creative Commons license, and indicate if changes were made. The Creative Commons Public Domain Dedication waiver (http://creativecommons.org/publicdomain/zero/1.0/) applies to the data made available in this article, unless otherwise stated. 


\section{Background}

The second leading cause of the cancer related deaths and the most common cancer evident in females worldwide is breast cancer. Based on the expression of estrogen/progesterone receptor and human epidermal growth receptor 2 , there are four major molecular intrinsic subtypes of breast cancer- luminal A $\left(\mathrm{ER}+/ \mathrm{HER}^{-}\right)$, luminal B (ER +/HER2-or HER2+), triple negative/basal type and HER2 type. Apart from these receptors there are receptors called estrogen-related receptors (ERRs) which share about $68 \%$ sequence homology in DNA binding domain (DBD) and significant sequence homology in ligand binding domain (LBD) with estrogen receptor [1]. No natural ligand is found to bind to these receptors giving them their names as orphan nuclear receptors [2]. Three closely related members ERR $\alpha, E R R \beta$ and ERR $\gamma$ constitute the ERR family. Among these, ERR $\alpha$ and ERR $\gamma$ play significant role as both transcriptional activator as well as repressor [3-11] in cancer and metabolism [1]. Less studied ERR $\beta[12,13]$ expression is lost during cancer progression, which indicates its tumor suppressive role, that still needs to be validated. Although association of ERRs with cancer is evident, fewer studies are there to address their amplified or reduced expression in breast cancer. Upon phosphorylation and PGC- $1 \alpha$ mediated regulation of most widely studied ERR $\alpha$ is reported $[14,15]$. However, regulation of ERR $\beta$ and ERR $\gamma$ in cancer is completely unknown. Unlike genetic changes, which are reversible, the capricious epigenetic alterations have evolved as captivating curative targets [16-18]. Dramatic increase in the experimental data in the epigenetic area gives the idea of the significance of epigenetic modifications in various stages of tumor progression. Enhancer of zeste homolog 2(EZH2), the catalytic component of polycomb repressive complex 2(PRC2) has been uncovered as an active transcriptional repressor. Amplified EZH2 expression results into deregulation of various genes relevant to signaling pathways in cancer and stem cell biology. A better understanding of regulation of orphan nuclear receptors through various epigenetic modifications might provide various opportunities for developing potential therapeutic targets. Present study investigates the role of EZH2 in regulation of ERRs in breast cancer. A significant association was found between estrogen-related receptors and EZH2. Existing negative correlation between them and recruitment of EZH2 on ERR $\alpha$ and ERR $\beta$ confirmed the ongoing in-vivo interaction between them. Overall, our results identify EZH2 as a functional coregulator for estrogen-related receptors especially ERR $\alpha$ and ERR $\beta$ in breast carcinoma.

\section{Methods}

Study approval and ethics statement:

All breast cancer specimens were collected with written informed consents from the patients and were approved by Institutional Human Ethical Committee (Institute of Life Sciences, Bhubaneswar, India). All human tumor samples were handled in accordance with an approved protocol of human ethical committee.

\section{Human breast Cancer patient samples}

Nineteen histologically similar breast tissues both cancerous and non-cancerous tissues (Additional file 1: Table S1) were used to prepare four identical tissue array slides. Using immunohistochemistry, EZH2, ERR $\alpha, E R R \beta$ and ERR $\gamma$ expression was simultaneously assessed in the breast tissue array.

\section{Immunohistochemistry}

Immunohistochemistry in array slides of patient samples was performed as previously described [19]. Slides were incubated with primary antibodies EZH2 (1:100) or $\operatorname{ERR} \alpha(1: 50)$ or $\operatorname{ERR} \beta$ (1:50) or ERR $\gamma$ (1:50) overnight at $4{ }^{\circ} \mathrm{C}$ and then subjected to incubation with anti-mouse/ rabbit IgG secondary antibody for $1 \mathrm{~h}$. Diaminobenzidine was used to detect the immunoreactivity. Slides were subsequently stained with haematoxylin and processed further. External negative control was taken for non-specific staining by primary antibody (Additional file 1: Figure S3). Stained slides were observed under light microscope (Leica DM500) and images were captured at $4 \mathrm{X}$ and $40 \mathrm{X}$ magnification. Pathologist scored all the stained slides as previously described [20]. Briefly, the staining intensity of cancerous cells was scored as: absent or weak, 1 point; moderate, 2 points; and strong, 3 points. Percentage positive tumor cells were scored as: 0 for percent of cells $<1,1$ for percent of cells between 1 and 10, 2 for percent of cells between 11 and 33, 3 for percent of cells between 34 and 66 and 4 for percent of cells between 67 and 100. Q score was calculated by multiplying intensity score by the score for percentage of antibody positive cancer cells.

\section{Cell culture}

MCF-7, T47D and MDA-MB-231 breast carcinoma cells were purchased from cell repository of National Centre for Cell Science Pune, Maharashtra, India (Additional file 1: Table S2) and were independently authenticated by STR analysis at Institute of Life Sciences, Bhubaneswar. T47D and MDA-MB-231 cells were maintained in Roswell Park Memorial Institute 1640 medium (RPMI) whereas MCF-7 was maintained in Dulbecco's Modified Eagle's Medium (DMEM) containing 10\% fetal bovine serum supplemented with penicillin-streptomycin at $37{ }^{\circ} \mathrm{C}, 5 \% \mathrm{CO}_{2}$ and 95\% humidity. MCF10A, a kind gift from Dr. Annapoorni Rangaranjan (IISC, Bangalore, India) was maintained in DMEM F12 containing horse serum (5\%) supplemented with hydrocortisone $(0.5 \mathrm{mg} / \mathrm{ml})$, EGF (20 ng/ml), insulin $(10 \mu \mathrm{g} / \mathrm{ml})$, cholera toxin $(100 \mathrm{ng} / \mathrm{ml})$ 
and penicillin-streptomycin at $37^{\circ} \mathrm{C}, 5 \% \mathrm{CO}_{2}$ and $95 \%$ humidity as previously described [21]. Cells were transfected with pCMV-EZH2 or EZH2si using Lipofectamine 3000 (Invitrogen) according to manufacturer's protocol. No ethical approval or informed consent was required to use any of the above-mentioned cell lines.

\section{Online dataset}

To investigate the association between EZH2 and estrogen-related receptors, we used online Metabolic gEne RApid Visualizer (MERAV) database (http://merav.wi.mit.edu/). MERAV is designed to analyze normalized human gene expression across 4454 arrays. Our study includes 196 different established and patient derived breast cancer cell line and 332 primary breast tumors of different grades \& histology types available in the dataset. The partial matrix provided in the database was used to calculate the Pearson correlation coefficient as a measure of strength of association. Each relative expression value was taken as a single data point.

\section{Plasmids, cell transfection}

Transient knockdown of EZH2 was performed by transfecting 80 pmoles of siRNA clusters (EZH2 antisense sequences: 5'-GGG-AAA-GUG-UAU-GAU-AAA-U55-3', 5'-AUU-UAU-CAU-ACA-CUU-UCC-C55-3', 5'-CAC -AAG-UCA-UCC-CAU-UAA-A55-3', 5'-UUU-AAU-G GG-AUG-ACU-UGU-G55-3', 5'-GGA-UGG-UAC-UU U-CAU-UGA-A55-3', 5'-UUC-AAU-GAA-AGU-ACC-AUC-C55-3') (Eurogentec). Universal negative Control siRNA (Eurogentec) was used as mock. Transient overexpression of EZH2 was performed by transfecting pCMV-EZH2 (Addgene, 24,230) in breast cancer cell lines. Breast cancer cells were transfected using Lipofectamine 3000 (Invitrogen) according to manufacturer's protocol.

\section{Western blot assay}

Whole cell lysates were prepared using RIPA lysis buffer that consisted of $20 \mathrm{mM}$ Tris- $\mathrm{HCl}(\mathrm{pH} 7.5) 150 \mathrm{mM}$ $\mathrm{NaCl}, 1 \mathrm{mM} \mathrm{Na}{ }_{2}$ EDTA, $1 \mathrm{mM}$ EGTA, 1\% triton X, 1\% sodium deoxycholate, $2.5 \mathrm{mM}$ sodium pyrophosphate, $1 \mathrm{mM} \beta$-glycerophosphate, $1 \mathrm{mM} \mathrm{Na} \mathrm{NO}_{3}$ and $1 \mu \mathrm{g} / \mathrm{ml}$ protease inhibitor. Equal amount of lysates were electrophoresed on 10\% SDS-polyacrylamide gel. The proteins were transferred onto Polyvinylidene difluoride (PVDF) membrane. After blocking the membrane in 5\% skimmed milk in tris-buffered saline (TBS) and Polysorbate 20 (Tween 20) TBS-T, incubation was done with primary antibodies against EZH2, ERR $\alpha, E R R \beta$ and ERR $\gamma$ overnight (List of reagents provided in the Additional file 1: Table S2). After washing, the membrane was incubated with anti-rabbit or anti-mouse horseradish peroxidase conjugated secondary antibody for one hour. After secondary antibody wash, the blot was developed for specific proteins using western bright ECL-HRP for X-ray Film Kit in Chemi-Doc (Bio-Rad).

\section{RNA isolation and quantitative real time PCR}

Total RNA was isolated from cells using Trizol (Sigma) as previously described [22]. Equal amount of DNase I treated RNA samples were used to prepare cDNA using SuperScript ${ }^{\circ}$ First-Strand Synthesis System for RT-PCR (Invitrogen, Carlsbad, CA) as per the manufacturer's instructions. Quantitative real time PCR was performed on Roche platform using SYBR Green (Thermo scientific) as per the guidelines using gene or site-specific primers (Additional file 1: Table S3). The mRNA level and fold change for each gene compared to control was calculated using value of cycle threshold value taking glyceraldehyde 3-phosphate dehydrogenase for normalization.

\section{Chromatin immunoprecipitation assay}

Breast cancer cells were grown to $90 \%$ confluence. CHIP assay was performed with anti-EZH2 as previously described [23] . Briefly, cells were cross-linked with $1 \%(v / v)$ formaldehyde, lysed in SDS lysis buffer and then sonication was done to obtain $200 \mathrm{bp}-500 \mathrm{bp}$ DNA fragments. Keeping aside the input control, the lysate was equally divided for negative control IgG and antibody of interest. De-crosslinking followed Immunoprecipitation with antibody after which DNA was eluted for CHIP-qPCR. The fold enrichment was determined as described previously [24].

\section{Statistical analyses}

Throughout the current study, two-tailed paired Student t-test, One-way ANOVA was performed to test the statistical significance of differences between the experimental groups using the software GraphPad Prism v5.01. Differences in data with values of * $P<0.05$, ** $P<0.005$ and ${ }^{* * *} P<0.001$ were considered statistically significant. Pearson correlation coefficient $(r)$ was calculated using the above mentioned software.

\section{Results \\ Expression of ERRa, ERR $\beta, E R R \gamma$ and EZH 2 in primary breast tumors of different grades}

To study the expression of EZH2 and ERRs in breast cancer patient samples, immunohistochemistry was performed simultaneously in four identical tissue arrays consisting nineteen cases with less histology variances. Although the expression of ERR $\alpha, E R R \beta$ and ERR $\gamma$ was not found to be tumor grade dependent, notable decrease in the trend of expression of ERR $\alpha, E R R \beta$ and ERR $\gamma$ was detected in increasing grade of breast tumor unlike that of EZH2, which showed a subsequent increased expression (Fig. 1a). Relative expression observed in online MERAV expression dataset 


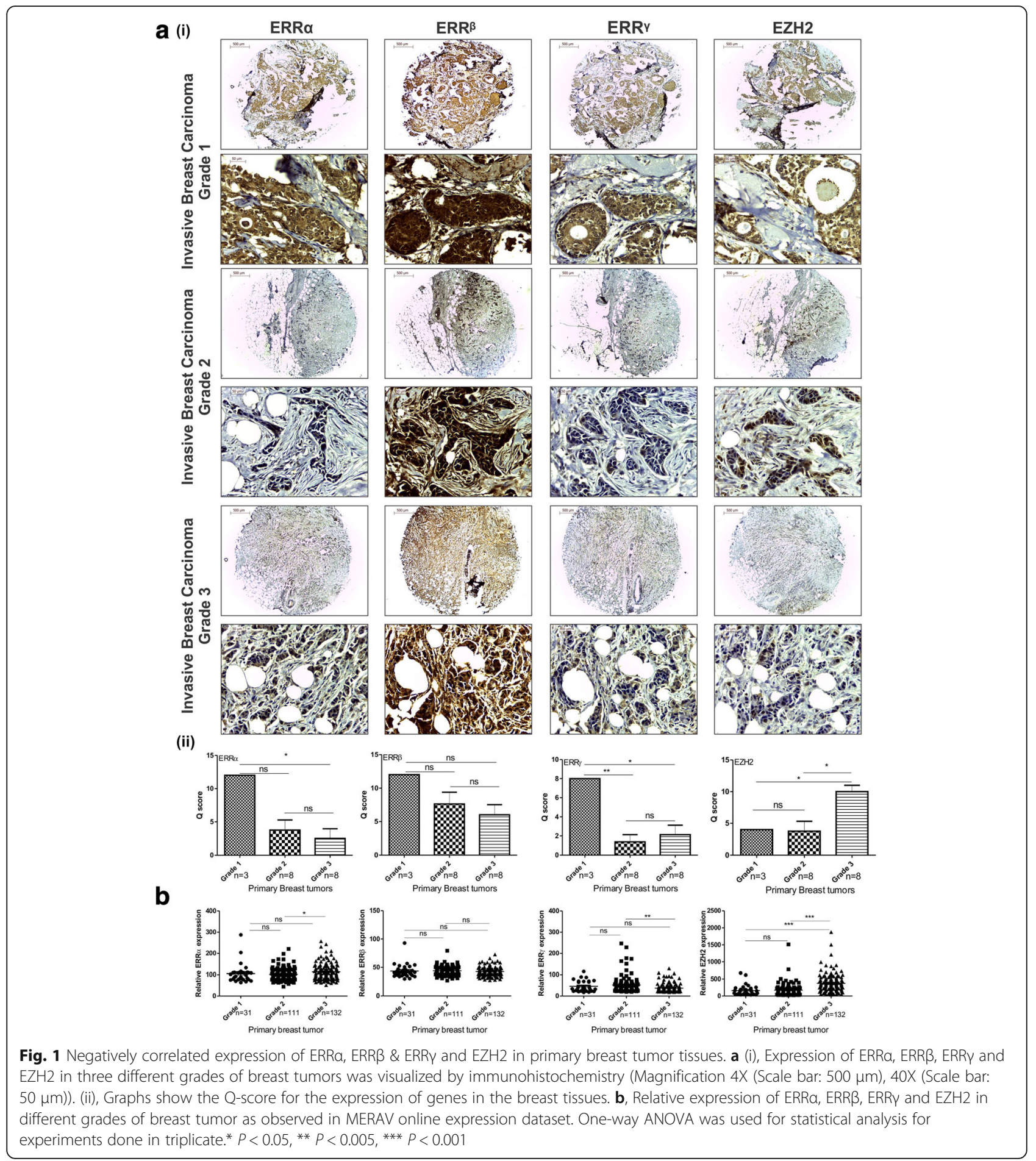

showed an enhanced EZH2 expression in primary breast tumors of increasing grade. However, similar to the pattern of expression observed in tissue arrays, the expression of ERRs was observed to be tumor grade independent (Fig. 1b).
In comparison to normal breast epithelial cells ERRa, $E R R \beta, E R R Y$ and EZH2 differentially express in breast cancerous cells

To investigate the expression pattern of EZH2 and orphan nuclear receptors in cell lines, we checked their 
expression using quantitative real time PCR \& immunoblot and by analyzing online data as well. In MERAV breast cancer cell line dataset, expression of ERR $\alpha$ and ERR $\beta$ displayed a reduced expression trend in cancerous cells in comparison to non-cancerous breast cells. However, expression of ERR $\gamma$ showed no specific trend. Reduced ERR $\gamma$ expression was observed in noncancerous breast cells in comparison to cancerous cells (Fig. 2a). Similar to expression found in primary breast tumors, increased expression of EZH2 was evidenced in breast cancer cells in comparison to normal breast epithelial cells both in MERAV dataset and cells under study in the laboratory. In real time and western blot assay, ERR $\alpha$ expression displayed no specific trend; ERR $\beta$ was highly expressed in MCF10A and less expressed in cancerous cells; ERR $\gamma$ expressed in both ER + ve and ER -ve cancerous cells but its reduced expression was found in normal breast epithelial MCF-10A cells (Fig. 2b, c). The expression pattern of EZH2 and ERR $\beta$ cells lines indicated a negative correlation between them, but the expression of ERR $\alpha$ and ERR $\gamma$ showed not such correlation. The significance of the data lies in the overall trend in the expression of EZH2 and ERRs in various breast cell lines.

\section{Correlation of estrogen-related receptors alpha beta and gamma with EZH2 expression}

Correlation is a statistical method that may be used to access the association between two genes. Pearson correlation coefficient is used as a measure of relationship between genes in terms of their expression [25]. A correlation coefficient of zero indicates that no linear relationship exists between two genes, and a correlation coefficient of -1 or +1 indicates a perfect linear relationship. The strength of relationship can be anywhere between -1 and +1 . If the coefficient is a positive

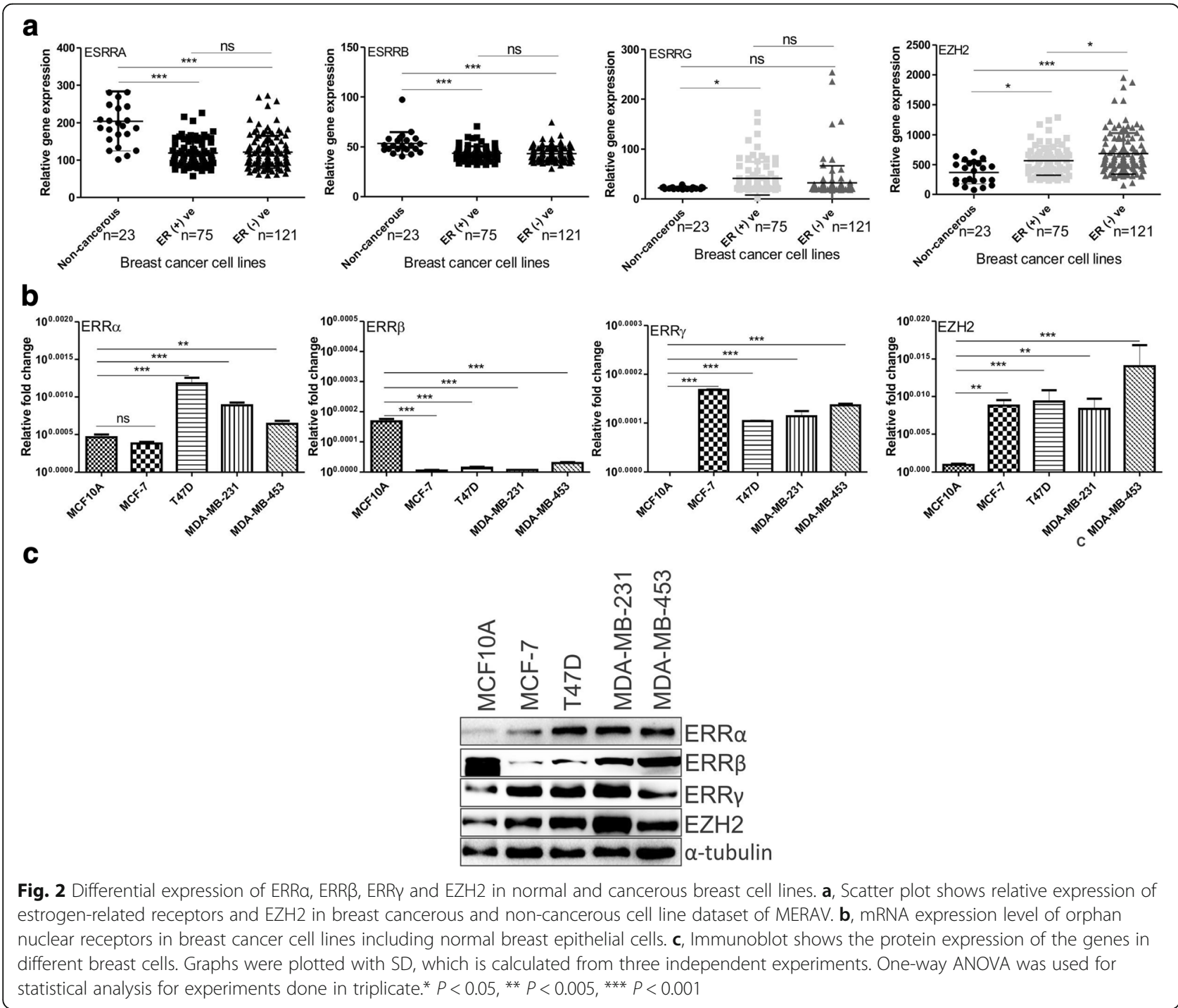


number, the variables are positively related. On the other hand, when the coefficient is a negative number, the expression of genes are inversely negatively related. If EZH2 regulates the expression of ERRs by its methyltransferase activity, a negative value of Pearson correlation coefficient is expected. Therefore, to define the type of association between EZH2 and ERRs, Pearson correlation coefficient values were calculated using the partial matrix values provided in the MERAV database. In normal breast epithelial cells, a negative correlation existed between relative expression of all three nuclear receptors and EZH2 (Fig. 3a). However a strong correlation was found between ERR $\gamma(r=-0.48)$ and EZH2 in comparison to ERR $\alpha(r=-0.16)$ and ERR $\beta(r=-0.018)$. A different strength of correlation was observed between ERRs and EZH2 in breast cancerous cells (Fig. 3b). A

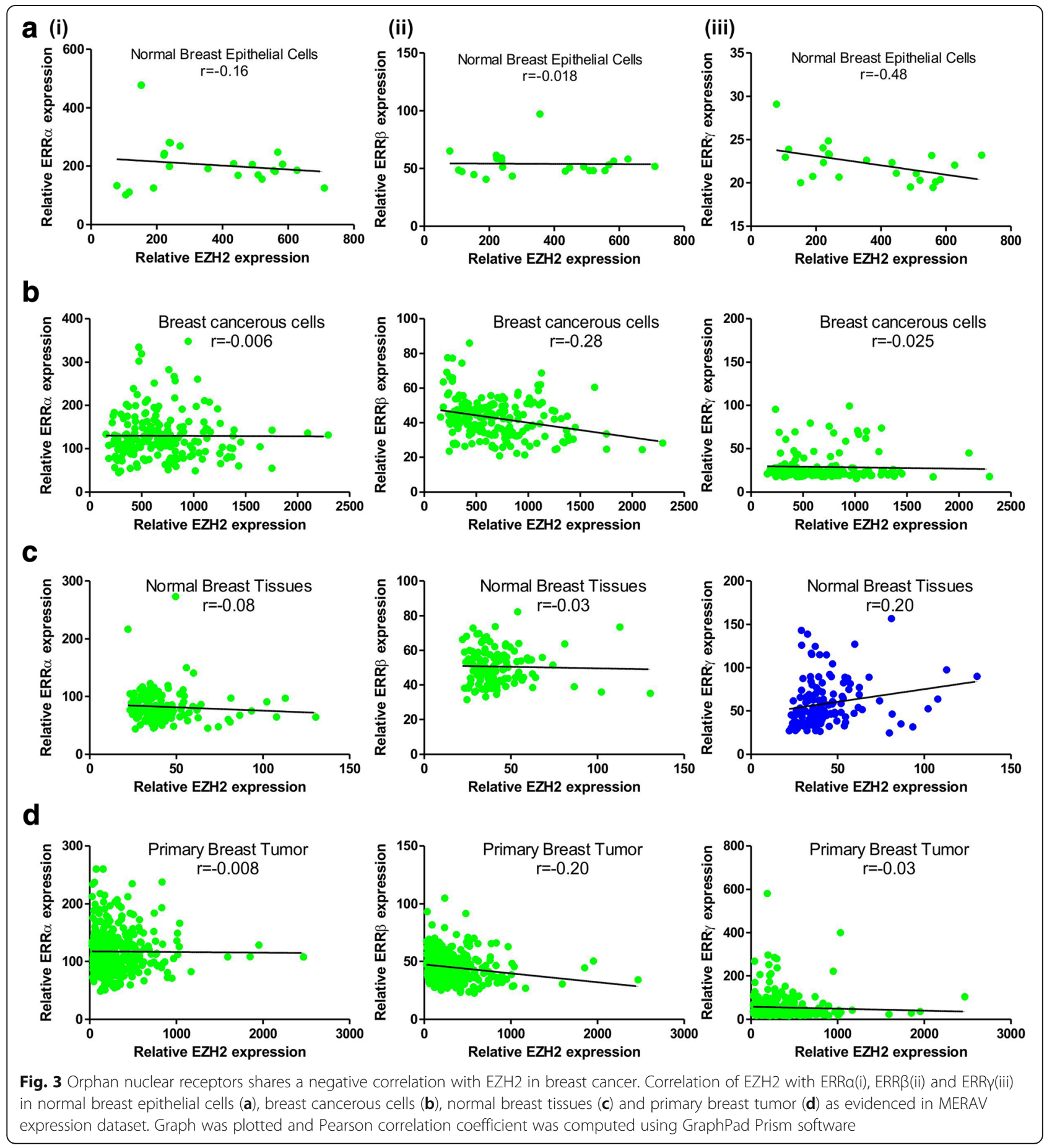


comparatively strong negative correlation was found between ERR $\beta$ and EZH2 $(r=-0.28)$ as between EZH2 and ERR $\alpha$ or ERR $\gamma$. In normal breast tissues, although weak, but a negative correlation was observed between $E Z H 2$ and ERR $\alpha$ or ERR $\beta$, however a strong positive correlation was found to exist between ERR $\gamma$ and EZH2 $(r=0.2)$ opposite to what observed in normal breast epithelial cells (Fig. 3c). Similar pattern of correlation as found in cancerous breast cells was evidenced in cancerous breast tissues with strong association between EZH2 and $\operatorname{ERR} \beta(\mathrm{r}=-0.2)$ (Fig. 3d).

\section{Ectopic expression of EZH2 reduces the expression of orphan nuclear receptors in normal breast epithelial MCF10A cells}

Further, to understand the regulation of orphan nuclear receptors by EZH2, we first checked their expression level after over-expressing EZH2 in cancerous MCF-7 cells and non-cancerous MCF10A cells (Fig. 4b (iii)). In high EZH2 expressing MCF-7 breast cancerous cells, the effect of EZH2 overexpression was not significant at both protein (Fig. 4a (i)) and RNA level (Fig. 4b (i)). However in less EZH2 harboring normal breast epithelial MCF10A cells, EZH2 overexpression resulted into significant reduced level of ERR $\alpha, E R R \beta$ and ERR $\gamma$ at protein (Fig. 4a (ii)) as well as RNA level (Fig. 4b (ii)).

\section{Silencing of EZH2 increases the expression of orphan nuclear receptors}

To further validate the EZH2-mediated regulation of ERRs, we next checked their expression upon EZH2 silencing. Transfection of EZH2si in breast cancer cells considerably reduced its level (Fig. 5b (iii)). In both estrogen receptor positive MCF-7 and estrogen receptor negative MDA-MB-231 breast cancer cells, significantly increased protein as well as RNA expression of ERR $\alpha$, ERR $\beta$ and ERR $\gamma$ was detected (Fig. 5a and b).

\section{$E Z H 2$ regulates ERRa and ERR $\beta$ by direct binding}

Further, to confirm the interaction of orphan nuclear receptors and polycomb group protein EZH2 in-vivo, we explored the CHIP-seq data performed in epithelial ovarian cancer cells upon EZH2 knockdown [26]. In the ChIP-seq data, EZH2 was found to directly bind to the genomic loci of ERR $\alpha$ at five putative binding sites (Fig. 6a) and ERR $\beta$ at 21 putative binding sites (we explored upto $10 \mathrm{~Kb}$ upstream and downstream of TSS) (Fig. 6c). The data suggested the binding of EZH2 on

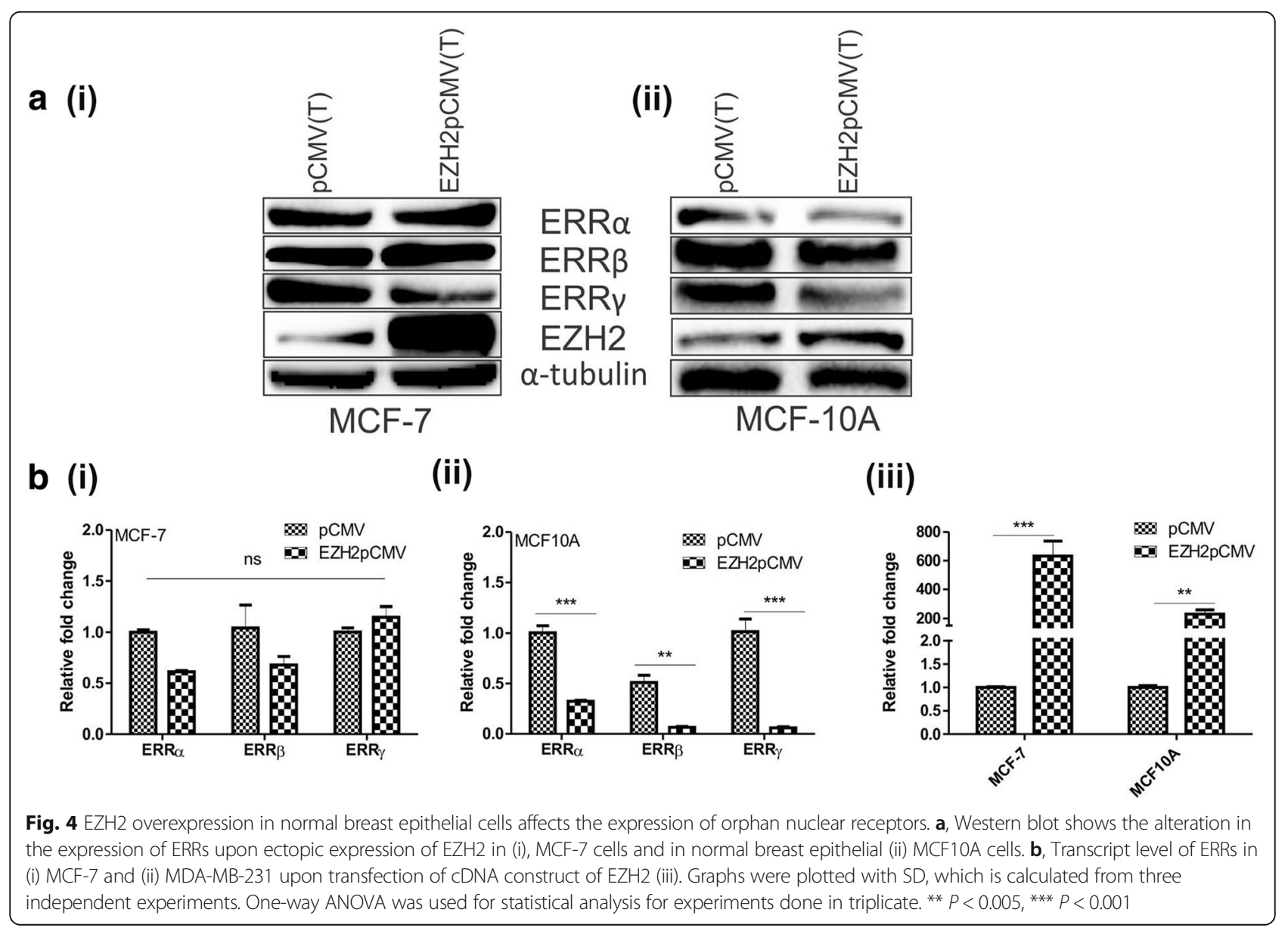




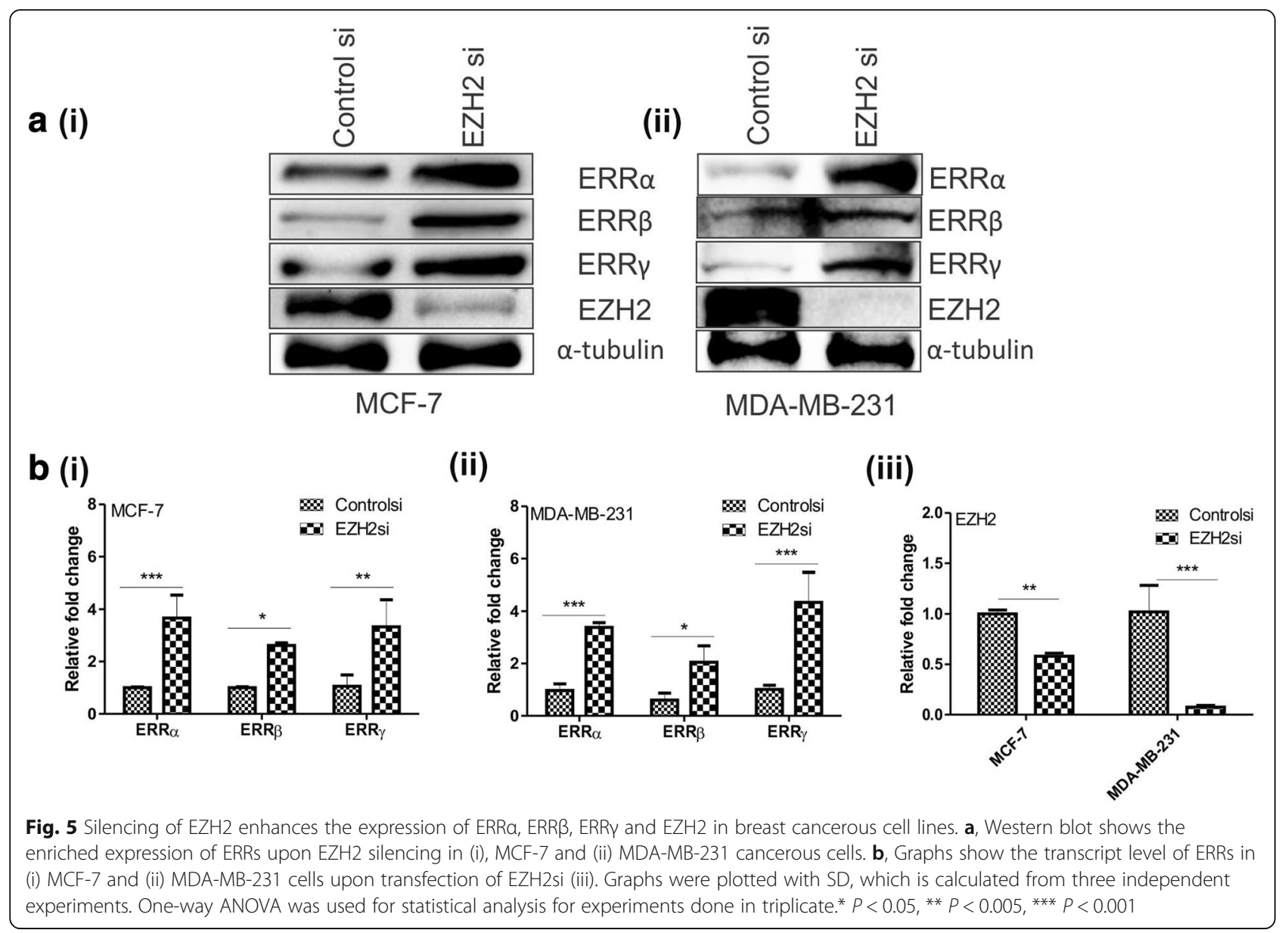

promoter region of ERR $\alpha$ and at both promoter as well as in-gene region of ERR $\beta$ for regulation. To confirm the protein-DNA binding we performed CHIP-qPCR by immunoprecipitation with EZH2 in MCF-7 breast cancer cells. Primers specific to the suggested region of binding were used for amplification. Input control was used for the amount of chromatin considered for the study and IgG was taken as negative control. By CHIP-qPCR three sites of ERR $\alpha$ (Fig. 6b) and two sites on ERR $\beta$ (Fig. 6d) was found to be occupied by EZH2 in both MCF-7 and MDA-MB-231 breast cancer cells (Additional file 1: Figure $S 1$ and S2 shows the agarose gel images of the CHIP -qPCR product). However, as no EZH2 binding sites were observed on ERR $\gamma$, regulation of ERR $\gamma$ by $\mathrm{EZH} 2$ may not be direct.

\section{Discussion}

Significant homology with estrogen receptors dictates the role of estrogen-related receptors (ERRs) in disease progression. Association of estrogen receptors with epigenetics $[27,28]$ reflects the possible involvement of epigenetics in the regulation of estrogen-related receptors as well. Reduced expression of ERR $\beta$ in breast cancer cells also anticipates the participation of repressor proteins for its regulation. Inter and intra-tumoral heterogeneity underlies the diverse pattern of expression of estrogen-related receptors in different grades of tumor as displayed by breast tumor dataset of MERAV. The MERAV breast cancer expression dataset consists of different histological types of tumor such as IDC, Ductal, Papillary, Medullary, Lobular, Inflammatory, Mucinous, Metaplastic Squamous Carcinoma etc. In addition, varied expression pattern of estrogen-related receptors observed in breast cells and tissues can be explained from the point that cell lines are derived from tumors and are grown and sub-cultured in vitro. Cell lines acquire changes in the process of immortalization and maintenance in culture. Here, in this study, we have shown the expression of ERRs in five different breast cell lines and histologically similar primary breast tumors; however, the online dataset displays the pattern observed in large number of cell lines maintained in different laboratories under different conditions, which answers the difference in the expression pattern [29-31]. A varied strength of negative correlation between EZH2 and ERRs further indicated the possible interaction between them. To 


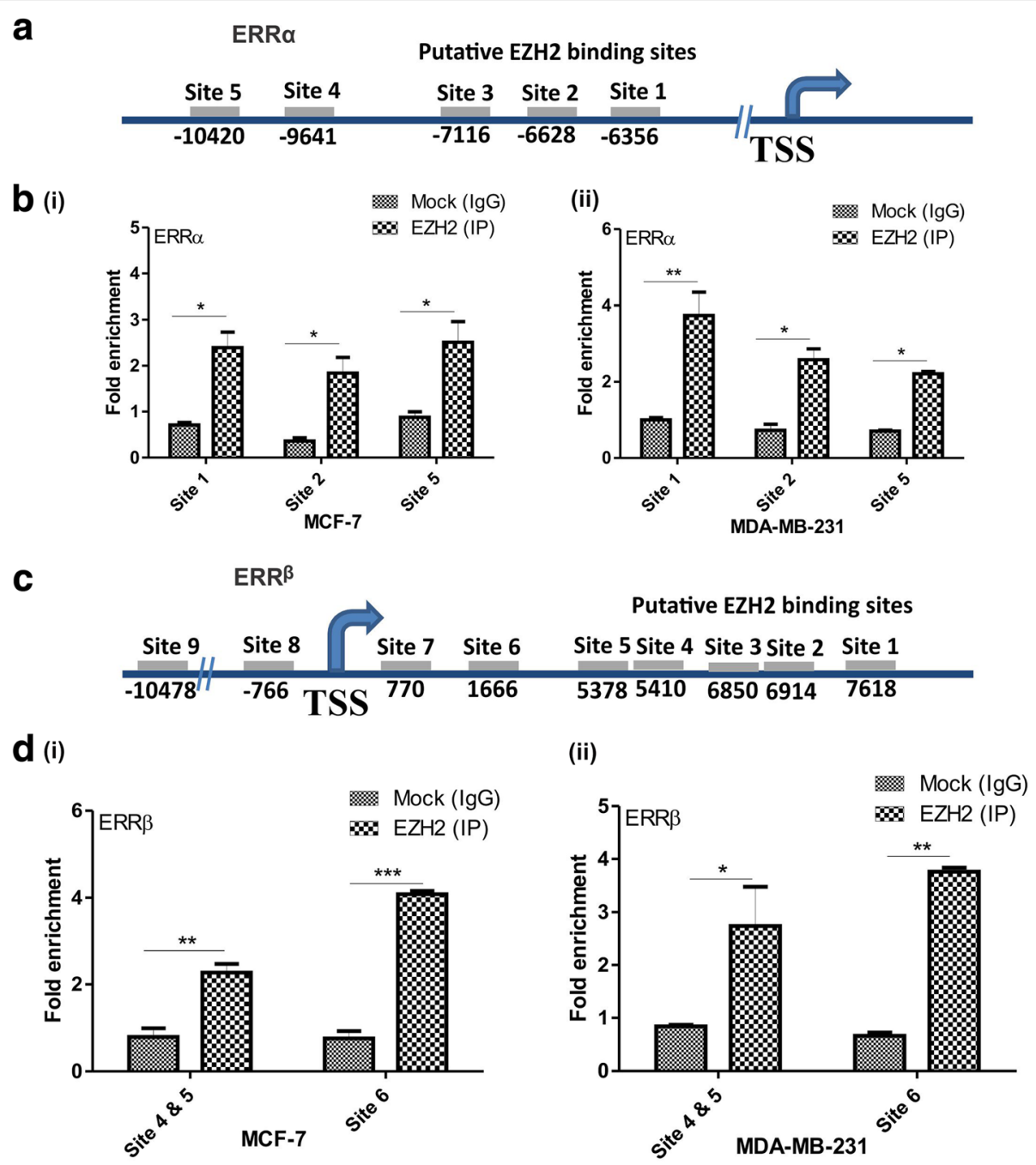

Fig. 6 EZH2 interacts with ERRa and ERRß in-vivo. a, Diagram shows the putative EZH2 binding sites on ERRa promoter. b, Graphs show the fold enrichment of EZH2 at two binding sites at ERRa promoter in MCF-7(i) and MDA-MB-231 (ii) cells. c. Diagram shows the putative EZH2 binding sites on ERRß promoter and downstream genomic loci. D, Graphs show the fold enrichment of EZH2 at two binding sites at in-gene region of ERR $\beta$ in MCF-7(i) and MDA-MB-231(ii) cells

investigate their association with global histone methyltransferase EZH2 we first checked the alteration in expression of ERRs upon EZH2 overexpression in cancerous ER positive MCF-7 cells, where insignificant or no change in expression of ERRs was found. In cancerous breast cells, endogenous level of EZH2 is high, thus upon its over-expression, it may reach its saturated level of expression. As evident from the graph of Fig. $4 \mathrm{~b}(\mathrm{i})$, although the effect of EZH2 overexpression shown non-significant effect on the expression of ERRs, when closely analyzed the percent knockdown in their expression, about $40 \%$ reduction in ERR $\alpha$ and about 35\% reduction in ERR $\beta$ level was observed. Expression of ERR $\gamma$ was enhanced by $14 \%$. This suggests that although the influence is not very effective, its effect is considerable for ERR $\alpha$ and ERR $\beta$. The degree of overexpression relative to the native level should vary strongly among the analyzed proteins. The absolute overexpression experiments analyze the consequences of comparably strong production of target proteins independently of their endogenous expression levels [32]. Such as if the endogenous expression of a target protein is 100 molecules/cell, the degree of overexpression will be likely 50,000 -fold. If the endogenous expression of a target protein is 100,000 molecules/cell, the overexpression degree will be 50 -fold. The fold change in EZH2 mRNA level upon overexpression was about 600 fold, but EZH2 protein was found to be only four fold increased when analyzed by ImageJ quantitation.

However, in low EZH2 expressing normal breast epithelial MCF-10A cells, significant reduced expression of ERRs was evident upon EZH2 overexpression. Significant 
enhanced expression of ERR $\alpha$, ERR $\beta$ and ERR $\gamma$ upon EZH2 silencing further strengthened the existing association between them. Occupancy of EZH2 on ERR $\alpha$ and ERR $\beta$ in EZH2-CHIP-seq data confirmed the possible interaction between EZH2 and ERRs. Well-studied ERR $\alpha$ and ERRY are biomarkers in breast cancer [10], but their role and regulation is not clear as they act as both transcriptional activator and repressor [11]. Association with co-activators and co-repressors might be the answers to their differential expression and thus function in cancer. As in CHIP-seq data, EZH2 was not found to occupy ERRY gene; the positive correlation between them in normal breast tissues supported the existence of an indirect association. Fold enrichment of EZH 2 on ERR $\alpha$ and ERR $\beta$ in CHIP-qPCR clearly showed in-vivo interaction between them. Although ERR $\alpha, E R R \beta$ and ERR $\gamma$ are prognostic markers for various cancers, their role and regulation is far from being clearly understood. Different study report inconsistent functions of ERR $\alpha$ [11, 33], ERR $\beta$ [12, 34, 35] and ERR $\gamma[8,36]$. Association of estrogen-related receptors with coregulators such as AIB1 [37] and EZH2 designates their regulation to be controlled by various factors. A better understanding of the regulation of ERRs will provide new insights into cancer biology.

\section{Conclusions}

Taken together our data suggests the regulation of estrogen-related receptors by global repressor gene, enhancer of zeste homolog 2. Transcription regulation of ERRs by coregulators such as EZH2 supports their inconsistent expression and function that is yet to be defined. Elucidation of such epigenetic regulations of orphan nuclear receptors will be helpful in understanding their role and regulation in breast carcinoma.

\section{Additional file}

Additional file 1: Tissue microarray patient sample details. Table provides the details of reagents used in the study. Table provides the sequence of primers used in the study. Agarose gel picture of CHIP-qPCR product for positive binding sites of EZH2 on ERRa and ERR $\beta$. Agarose gel picture of CHIP-qPCR product for negative binding sites of EZH2 on ERRa and ERR $\beta$ Immunohistochemistry negative control cases for primary antibodies ERRa, ERRß, ERRY and EZH2. Table S1. Tissue microarray patient sample details. Nineteen breast carcinoma patient samples were included in the the study. Table S2. Table provides the details of reagents used in the study. All reagents used in the study were obtained from authentic companies. Table S3. Table provides the sequence of primers used in the study. Figure S1. Agarose gel picture of CHIP-qPCR product for positive binding sites of EZHZ2 on ERRa and ERR $\beta$. Figure S2. Agarose gel picture of $C H I P-q P C R$ product for negative binding sites of $E Z \mathrm{H} 2$ on ERRa and ERR $\beta$. Figure S3. Immunohistochemistry negative control cases for primary antibodies ERRa, ERRß, ERRY and EZH2. (PDF 757 kb)

\section{Abbreviations}

AIB1: Amplified in breast cancer-1; EGF: Epidermal growth factor; ERRs: Estrogen-related receptors; EZH2: Enhancer of zeste homolog 2; MERAV: Metabolic gEne RApid Visualizer; pCMV: plasmid cytomegalovirus; r: Pearson correlation coefficient; SD: Standard deviation; STR: Short Tandem Repeat; TSS: Transcription start site

\section{Acknowledgements}

We acknowledge Department of Biotechnology, Govt of India and Department of Science and Technology, Govt. Of India for the funding. We also acknowledge the Director, Institute of Life Sciences, for the core grant as well as his support in the performance of this project.

Availability of data and materials

All relevant raw data will be provided as per requirement.

- The expression datasets used and analyzed to generate the correlation data are available in the MERAV database (http:// merav.wi.mit.edu/)

- The CHIP-seq dataset analyzed in the study is available as supplementary material in excel sheet format with the published article $(\mathrm{Li} \mathrm{H}$, Bitler BG, Vathipadiekal V, et al. ALDH1A1 is a novel EZH2 target gene in epithelial ovarian cancer identified by genome-wide approaches. Cancer Prevention Research (Philadelphia, Pa). 2012;5(3):484-491. doi:https://doi.org/10.1158/1940-6207.CAPR-11-0414.)

Authors' contributions

Acquisition of data: KK, AKA, AKR, PBR. Analysis and interpretation of data: KK, AKA, AKR, SKM. Drafting of manuscript: KK AKR, PBR. Critical revision: KK, SKM. Overall guidance: KK, SKM. All authors read and approved the final manuscript.

Ethics approval and consent to participate

All breast cancer specimens were collected with written informed consents from the patients and were approved by Institutional Human Ethical Committee (Institute of Life Sciences, Bhubaneswar, India). All human tumor samples were handled in accordance with an approved protocol of human ethical committee.

\section{Consent for publication}

NA.

Competing interests

The authors declare that they have no competing interests.

\section{Publisher's Note}

Springer Nature remains neutral with regard to jurisdictional claims in published maps and institutional affiliations.

\section{Author details}

${ }^{1}$ Cancer Biology Laboratory, Department of Gene Function and Regulation, Institute of Life Sciences, Bhubaneswar. Utkal University, Bhubaneswar, Odisha, India. ${ }^{2}$ Department of Pathology, AllMS, Bhubaneswar, Odisha, India. ${ }^{3}$ Hemalata Hospitals, Chandrashekharpur, Bhubaneswar, Odisha, India. ${ }^{4}$ Department of Microbiology and Biotechnology, Govt. PG College Ratlam, Ratlam, MP, India.

Received: 6 April 2018 Accepted: 12 June 2018 Published online: 26 June 2018

\section{References}

1. Huss JM, Garbacz WG, Xie W. Constitutive activities of estrogen-related receptors: transcriptional regulation of metabolism by the ERR pathways in health and disease. Biochim Biophys Acta. 2015;1852(9):1912-27.

2. Giguere V. Orphan nuclear receptors: from gene to function. Endocr Rev. 1999:20(5):689-725.

3. May FE. Novel drugs that target the estrogen-related receptor alpha: their therapeutic potential in breast cancer. Cancer Manag Res. 2014;6:225-52.

4. Audet-Walsh E, Papadopoli DJ, Gravel SP, Yee T, Bridon G, Caron M, Bourque G, Giguere V, St-Pierre J. The PGC-1alpha/ERRalpha Axis represses one-carbon metabolism and promotes sensitivity to anti-folate therapy in breast Cancer. Cell Rep. 2016;14(4):920-31.

5. Ochnik AM, Yee D. Estrogen-related receptor alpha: an orphan finds a family. Breast cancer research : BCR. 2012;14(3):309. 
6. Stein RA, Chang CY, Kazmin DA, Way J, Schroeder T, Wergin M, Dewhirst MW, McDonnell DP. Estrogen-related receptor alpha is critical for the growth of estrogen receptor-negative breast cancer. Cancer Res. 2008; 68(21):8805-12.

7. Tiwari A, Swamy S, Gopinath KS, Kumar A. Genomic amplification upregulates estrogen-related receptor alpha and its depletion inhibits oral squamous cell carcinoma tumors in vivo. Sci Rep. 2015;5:17621.

8. Tiraby C, Hazen BC, Gantner ML, Kralli A. Estrogen-related receptor gamma promotes mesenchymal-to-epithelial transition and suppresses breast tumor growth. Cancer Res. 2011;71(7):2518-28.

9. Deblois $\mathrm{G}$, Giguere V. Oestrogen-related receptors in breast cancer: control of cellular metabolism and beyond. Nat Rev Cancer. 2013;13(1):27-36.

10. Ariazi EA, Clark GM, Mertz JE. Estrogen-related receptor alpha and estrogenrelated receptor gamma associate with unfavorable and favorable biomarkers, respectively, in human breast cancer. Cancer research. 2002; 62(22):6510-8

11. Kraus RJ, Ariazi EA, Farrell ML, Mertz JE. Estrogen-related receptor alpha actively antagonizes estrogen receptor-regulated transcription in MCF-7 mammary cells. J Biol Chem. 2002;277(27):24826-34.

12. Sengupta D, Bhargava DK, Dixit A, Sahoo BS, Biswas S, Biswas G, Mishra SK ERRbeta signalling through FST and BCAS2 inhibits cellular proliferation in breast cancer cells. Br J Cancer. 2014;110(8):2144-58.

13. Divekar SD, Tiek DM, Fernandez A, Riggins RB. Estrogen-related receptor beta (ERRbeta) - renaissance receptor or receptor renaissance? Nucl Recept Signal. 2016;14:e002.

14. Ariazi EA, Kraus RJ, Farrell ML, Jordan VC, Mertz JE. Estrogen-related receptor alpha1 transcriptional activities are regulated in part via the ErbB2/HER2 signaling pathway. Mol Cancer Res. 2007;5(1):71-85.

15. Liu D, Zhang Z, Teng CT. Estrogen-related receptor-gamma and peroxisome proliferator-activated receptor-gamma coactivator-1alpha regulate estrogenrelated receptor-alpha gene expression via a conserved multi-hormone response element. J Mol Endocrinol. 2005;34(2):473-87.

16. Serrano-Gomez SJ, Maziveyi M, Alahari SK. Regulation of epithelialmesenchymal transition through epigenetic and post-translational modifications. Mol Cancer. 2016;15:18.

17. Arrowsmith $\mathrm{CH}$, Bountra C, Fish PV, Lee K, Schapira M. Epigenetic protein families: a new frontier for drug discovery. Nat Rev Drug Discov. 2012;11(5): 384-400.

18. Jones PA, Issa JP, Baylin S. Targeting the cancer epigenome for therapy. Nat Rev Genet. 2016;17(10):630-41.

19. Watson AS, Soilleux EJ. Detection of p62 on paraffin sections by immunohistochemistry. Cold Spring Harb Protoc. 2015;2015(8):756-60.

20. McDonald JW, Pilgram TK. Nuclear expression of p53, p21 and cyclin D1 is increased in bronchioloalveolar carcinoma. Histopathology. 1999;34(5):439-46.

21. Debnath J, Muthuswamy SK, Brugge JS. Morphogenesis and oncogenesis of MCF-10A mammary epithelial acini grown in three-dimensional basement membrane cultures. Methods. 2003;30(3):256-68.

22. Rio DC, Ares M Jr, Hannon GJ, Nilsen TW. Purification of RNA using TRIzol (TRI reagent). Cold Spring Harb Protoc. 2010;2010(6):pdb prot5439.

23. Carey MF, Peterson CL, Smale ST. Chromatin immunoprecipitation (ChIP). Cold Spring Harb Protoc. 2009;2009(9):pdb prot5279.

24. Lacazette E. A laboratory practical illustrating the use of the ChIP-qPCR method in a robust model: estrogen receptor alpha immunoprecipitation using Mcf-7 culture cells. Biochem Mol Biol Educ. 2017;45(2):152-60.

25. Bhardwaj N, Lu H. Correlation between gene expression profiles and protein-protein interactions within and across genomes. Bioinformatics. 2005;21(11):2730-8.

26. Li H, Bitler BG, Vathipadiekal V, Maradeo ME, Slifker M, Creasy CL, Tummino PJ, Cairns P, Birrer MJ, Zhang R. ALDH1A1 is a novel EZH2 target gene in epithelial ovarian cancer identified by genome-wide approaches. Cancer Prev Res. 2012;5(3):484-91.

27. Ianov L, Kumar A, Foster TC. Epigenetic regulation of estrogen receptor alpha contributes to age-related differences in transcription across the hippocampal regions CA1 and CA3. Neurobiol Aging. 2017;49:79-85.

28. Zhou Q, Shaw PG, Davidson NE. Epigenetics meets estrogen receptor: regulation of estrogen receptor by direct lysine methylation. Endocr Relat Cancer. 2009;16(2):319-23.

29. Domcke S, Sinha R, Levine DA, Sander C, Schultz N. Evaluating cell lines as tumour models by comparison of genomic profiles. Nat Commun. 2013;4:2126.

30. Sandberg R, Ernberg I. The molecular portrait of in vitro growth by metaanalysis of gene-expression profiles. Genome Biol. 2005;6(8):R65.
31. Ross DT, Scherf U, Eisen MB, Perou CM, Rees C, Spellman P, lyer V, Jeffrey SS, Van de Rijn M, Waltham $\mathrm{M}$, et al. Systematic variation in gene expression patterns in human cancer cell lines. Nat Genet. 2000;24(3):227-35.

32. Moriya H. Quantitative nature of overexpression experiments. Mol Biol Cell. 2015;26(22):3932-9.

33. Fradet A, Sorel H, Bouazza L, Goehrig D, Depalle B, Bellahcene A, Castronovo V, Follet $\mathrm{H}$, Descotes F, Aubin JE, et al. Dual function of ERRalpha in breast cancer and bone metastasis formation: implication of VEGF and osteoprotegerin. Cancer Res. 2011;71(17):5728-38.

34. Lu D, Kiriyama Y, Lee KY, Giguere V. Transcriptional regulation of the estrogen-inducible pS2 breast cancer marker gene by the ERR family of orphan nuclear receptors. Cancer Res. 2001;61(18):6755-61.

35. Yu S, Wong YC, Wang XH, Ling MT, Ng CF, Chen S, Chan FL. Orphan nuclear receptor estrogen-related receptor-beta suppresses in vitro and in vivo growth of prostate cancer cells via p21(WAF1/CIP1) induction and as a potential therapeutic target in prostate cancer. Oncogene. 2008;27(23): 3313-28.

36. Yu S, Wang X, Ng CF, Chen S, Chan FL. ERRgamma suppresses cell proliferation and tumor growth of androgen-sensitive and androgeninsensitive prostate cancer cells and its implication as a therapeutic target for prostate cancer. Cancer Res. 2007;67(10):4904-14.

37. Heck S, Rom J, Thewes V, Becker N, Blume B, Sinn HP, Deuschle U, Sohn C, Schneeweiss A, Lichter P. Estrogen-related receptor alpha expression and function is associated with the transcriptional coregulator AIB1 in breast carcinoma. Cancer Res. 2009;69(12):5186-93.

\section{Ready to submit your research? Choose BMC and benefit from:}

- fast, convenient online submission

- thorough peer review by experienced researchers in your field

- rapid publication on acceptance

- support for research data, including large and complex data types

- gold Open Access which fosters wider collaboration and increased citations

- maximum visibility for your research: over $100 \mathrm{M}$ website views per year

At BMC, research is always in progress.

Learn more biomedcentral.com/submissions 